\title{
Effect of culture on women physicists' career choice: A comparison of Muslim majority countries and the West
}

\author{
Saeed Moshfeghyeganeh ${ }^{1,2,3,4,{ }^{*}}$ and Zahra Hazari ${ }^{1,2,3}$ \\ ${ }^{1}$ STEM Transformation Institute, Florida International University Modesto A. Maidique Campus, \\ 11200 SW 8th Street, Miami, Florida 33199, USA \\ ${ }^{2}$ Department of Teaching and Learning, Florida International University Modesto A. Maidique Campus, \\ 11200 SW 8th Street, Miami, Florida 33199, USA \\ ${ }^{3}$ Department of Physics, Florida International University Modesto A. Maidique Campus, \\ 11200 SW 8th Street, Miami, Florida 33199, USA \\ ${ }^{4}$ Mohsin \& Fauzia Jaffer Center for Muslim World Studies, Florida International University, \\ Modesto A. Maidique Campus, 11200 SW 8th Street, Miami, Florida 33199, USA
}

(Received 17 August 2020; accepted 25 February 2021; published 8 March 2021)

\begin{abstract}
Women continue to be underrepresented in physics in the United States. This is while many Muslim majority (MM) countries have a high representation of women in undergraduate and graduate physics programs. While there is a growing awareness of this trend, little is being done to understand why and how this trend has manifested and how it can be used to inform broadening the participation of women in physics in the U.S. To better understand how cultural experiences can influence the pursuit of physics, this study examines the lived experiences of female physics faculty members in the U.S. who came from MM countries. The study draws on seven phenomenological interviews focusing on how cultural experiences shaped participants' gender and physics identities. The results reveal several possible hypotheses on differences and similarities in how physics and gender identities intersect in MM countries as opposed to what has been found in the West. In particular, expressions of femininity in MM countries can have a more constructive intersection with expressions of physics identity in ways that promote participation and persistence.
\end{abstract}

DOI: 10.1103/PhysRevPhysEducRes.17.010114

\section{INTRODUCTION}

The underrepresentation of women in physics has been a persistent concern in many countries (including the U.S.) and attempts to increase women's representation in physics have not been very successful [1]. In the past, while women's representation in physics in the U.S. was increasing, it has stagnated at around $20 \%$ for more than a decade $[2,3]$. To better address the underrepresentation of women in physics and factors contributing to this problem, researchers have attempted to understand these factors from various perspectives. From studies focusing on the influence of others including parents, teachers, peers, the scientific community, etc., [4-7], to classroom and curricular level work [8-10], there has been considerable growth in understanding women's physics interests in Western contexts. However, this problem cannot be meaningfully addressed unless we better understand the underlying cultural values that drive the problem and address

\footnotetext{
*smoshfeg@fiu.edu
}

Published by the American Physical Society under the terms of the Creative Commons Attribution 4.0 International license. Further distribution of this work must maintain attribution to the author(s) and the published article's title, journal citation, and DOI. questions such as the following: what does it mean to be a physicist, what does it mean to be a woman, and what is it about being a physicist and a woman that make these identities culturally incongruent.

Learning physics does not merely entail gaining knowledge and acquiring the ability to solve problems, but also entails a process of identity formation [11]. In the process of learning physics students become familiar with what is considered relevant and irrelevant, how to approach what is considered relevant, and how to present their thoughts and answers in a way that is understandable by the physics community. During this process, students learn how to become part of the physics community and to act based on the norms of this community [12]. As a result, particular attitudes, attributes, and identities, although not explicitly rejected, may be considered incongruent with the physics community's norms. As such, those who possess these attributes and identities are not considered to fully fit in the physics community and might feel rejection. Since physics identities are aligned with white and masculine norms [5], women and people of color do not fit these norms and must either abandon expressing some of their identities to fit in the norms of the physics community or leave altogether.

However, there is no reason to believe that these cultural norms, congruences, and incongruences, are the same around the globe. As we know gender has a strong cultural 
component $[13,14]$ which implies that femininity and masculinity can be defined differently in different social contexts. Thus, although femininity and physics culture are perceived as incongruent in Western societies, this might not be the case in other cultures. Focusing on Muslim majority (MM) countries in terms of the involvement of women in physics, we see a very different trend with very high rates of women's participation in physics $(60 \%)$ in countries like Egypt and Iran $[15,16]$. Considering the fact that there are significant cultural differences between MM and Western countries [17,18], these differences can contribute to the participation of women in physics. Furthermore, MM countries themselves have cultural similarities and differences. However, just like there are similarities across Western countries such that researchers have studied "Western culture," there are also similarities in culture across MM countries that have been connected to "Islamic culture." For example, Islamic culture tends to emphasize similar social aspects of human life $[17,19]$. The Islamic faith shapes many aspects of its members' life including beliefs, lifestyle, and law [17,20,21]. However, MM countries cultures are not monolithic and have many different variations based on region and ethnicity. For example, while women across these cultures may have different ethnic forms of dress, they have a common emphasis on modesty based on Islamic principles [22]. As a result, MM countries that are extended from east Asia to west Africa, might have different cultural expressions but are guided by similar cultural values and principles. It should be noted that for a long time, Muslim women have been portrayed as oppressed and backward by gender orientalists [23-25]. This distorted picture has resulted from a lack of cultural understanding.

To understand the cultural experiences that facilitate the participation of women in physics, this study explores the lived experience of seven U.S. female physics faculty members who came from MM countries. The experience of multiple cultures that these female physicists had in the U.S. and MM countries provides insight with regards to femininity and physics identity across these contexts. The results of this study revealed five different hypotheses regarding femininity and physics identity in MM countries. In comparing these results with cultural findings from the West, this work can be used to enhance cultural understanding of physics participation in MM contexts as well as reveal potentially novel approaches to improving the participation of women in physics in the U.S. and other Western contexts where underrepresentation is a persistent issue.

\section{THEORETICAL BACKGROUND}

In this paper, we adopt the terminology of gender as referring to psychological, social, and cultural aspects, particularly with respect to maleness and femaleness [26]. As such we define femininity as the attributes, characteristics, ways of thinking or being that are more attributed to a female gender identity within a culture. By internalizing and incorporating these cultural meanings, gender becomes part of an individual's identity, i.e., how they see themselves and present themselves to others [27]. One way that gender identity has been studied is by examining gender-stereotypic personality traits [28,29]. This framework looks at traits that are culturally associated with being masculine or feminine and examines individuals' gender identities based on their association with these traits. Another trend in research on gender identity is to examine gender identity as it relates to how individuals see themselves. In this trend, instead of making pre-assumptions about the implications of different traits on gender identity, individuals identify themselves as members of specific gender groups and express the importance of this membership on their identity [27]. In this approach, an individual's gender identity may become more salient depending on the context; in some contexts, their expression and identification with their gender is centrally important to who they are and how they want to be seen by others while in other contexts, it may be less important than other identities they ascribe to [27,30].

Similar to the development of research on gender identity, in physics education there has been some development of physics identity research and the role of becoming part of a community of practice [31-33]. More specifically, physics education has evolved in the last few decades from the perspective of learning merely as gaining knowledge to learning as the process of becoming a member of the physics community [13,31-35]. This membership entails the ability to communicate in a language that is understandable by the physics community and act based on the particular norms of this community [35]. In other words, physicists learn what kinds of things to know and what types of desires to value in order to be considered serious in the physics community [12]. As a result, we can claim that science, and particularly physics, satisfy the definition of a culture [36,37].

In this sociocultural approach, learning physics requires moving from one's other subcultures (family, friends, social class, ...) to the culture of physics classrooms and the physics community. Although this transition is smooth for some students, it can be challenging for many. This challenge is related to cultural congruency [36] as a measure of the similarities between the two cultures. The students who enter a new culture have to cross the border between the two cultures. For congruent cultures, this border crossing is smooth while it can be hazardous or impossible for incongruent cultures [37,38]. Costa [39] categorizes border crossings based on the congruity level of the students' background culture with science culture. Krogh et al. identified nine types of cultural border crossings for students who enter the physics culture [40]. Their work identified a negative relationship between the number of border crossings a student has to traverse and choosing 
higher level physics courses. Ethier and Deuax further elaborated on how entering into a new culture can threaten preexisting identities of students [41].

Drawing on these studies, we attempt to develop a better understanding about the congruity or incongruity between gender and physics identities across different cultures (in this case, MM countries as compared to prior research from Western contexts). This paper focuses on how gender identity (how individuals see their own gender and perceptions of femininity or masculinity in social contexts) and physics identity (how individuals see themselves with respect to the physics community and perceptions of physics) can be different across cultures, which may make these identities more or less congruent. First, we review literature on physics identity and femininity and how they have been found to be incongruent in Western contexts (e.g., U.S., Canada, U.K., and Germany). Then we draw on evidence from interviews with female physicists who experienced both MM and Western contexts to describe five different hypotheses explaining why there may be greater congruity between physics and femininity in $\mathrm{MM}$ countries and subsequently higher female representation.

\section{A. Physics, social interaction, single-sex environments, and femininity}

In the U.S., women are stereotyped as being more social than men $[26,42,43]$. For example, Knox et al. showed there is a significant difference in the level of loneliness between male and female college students with male students reporting that they were less likely to be in relationships or know how to make friends than female students [44]. Other studies also showed a higher level of social connectedness for women than men such as their higher level of social interaction and value for physical proximity than men $[45,46]$. From an older perspective in the psychology literature that ascribed femininity or masculinity more to innate nature than being socially constructed (i.e., taught gender roles), Cross and Madson suggested that men are fundamentally less social beings than women, implying that social bonds and interactions are innately more important to women than men [47]. These studies draw conclusions regarding the relationship between social connectedness and masculinity or femininity from data collected in Western contexts.

This is while the image of a scientist for a long time has been a middle-aged white man who works alone $[48,49]$. Hannover and Kessels found that students who favored science were judged as more unpopular, i.e., less likely to be socially connected, and more unattractive [49]. These students were also perceived as less socially competent and less integrated into communities with their peers. In a similar study, Bruun et al. studied stereotypes about physicists [50]. They found that physicists are perceived as single minded individuals with poor interpersonal skills who are not attractive. As before, these studies draw on data from Western contexts and shed light on not only the relationship between gendered expectations or patterns of social connectedness but also how social connectedness relates to perceptions of the types of people who have a physics identity.

In spite of the image of women as more social and interactive, boys have been found to dominate teacherstudent interactions in physics classes [51,52]. It is also reported that in lab settings, boys control the experiments and lab equipment where girls passively watch, take notes, or do what boys tell them to do $[53,54]$. This may be a consequence of the competitive structure of physics classes where students need to compete in order to be recognized and gain the teacher's attention and resources or opportunities. However, this competitive structure may harm girls since women have been found to perform worse or shy away from competitive situations in mixed settings [55,56]. Similarly, young women have been found to opt out of engaging in active learning physics environments as these environments can threaten their sense of self as good students [57]. In addition, the presence of male students in these environments might exacerbate their feeling less competent, especially if the environment has limited support and affective scaffolding.

It has been suggested that there is greater pressure for girls, compared to boys, to maintain their gender identity in schools where boys are present [58]. Considering that physics is stereotyped as a masculine subject, "adolescent girls in a mixed gender environment could be subject to more conflict in their gender identity since they have to compete with boys while at the same time they may feel pressured to behave in a 'feminine manner' to be attractive to boys." Similarly, in mixed-sex classes, boys endorse more masculine traits and describe themselves in a more gender-stereotyped way [59]. On the other hand, in singlesex classes, gender-related comparisons and self-awareness is less salient. As Kessels suggests, when all group or class members are of the same sex, gender is not a useful category to describe or differentiate them [59]. Interestingly, Booth and Noel found that a girl's environment plays an important role in her tendency to compete; girls in single-sex schools exhibit more competitiveness than girls in coeducational settings [60]. In sum, female students' engagement or interactiveness within academic environments is likely influenced by the presence of male students despite the fact that females have been found to be more socially interactive in broader society.

We have to keep in mind that there are conflicting results about the effect of single-sex education on interest in physics and intentions to pursue physics careers.

Several studies have found that female students with single-sex physics experiences have a stronger self-concept about their ability in physics [59,61-63]. Others observed a 
higher sense of belonging [64], better performance in physics [51,52], and greater persistence in physics when exposed to single-sex classes $[51,65,66]$. In contrast, some research showed no gain for girls in single-sex schools compared to coeducation [67-70]. These contradicting reports can be the result of different contextual features of the environments being studied with other factors playing a role in the efficacy of single-sex physics education. For example, in the West, single-sex schools are very selective which leads to nonequivalent group comparison $[71,72]$. Others proposed that single-sex education can be effective if it is accompanied with changes in curriculum or teachers' attitudes towards gender issues in physics $[62,73]$. In addition, research in the U.S. shows that stereotypes about boys being smarter than girls starts as early as the age of six [74], which is the age most students start elementary school. Consequently, high school girls in the U.S. who are taking a single-sex physics class may have been exposed to gender stereotypes for several years prior to taking the course and already internalized these views. As such, it would be difficult to change years of gendered enculturation with one single-sex class in physics.

\section{B. Physics, religion, and femininity}

Events like the Inquisition of Galilio led some historians of science like John Draper to propose a "conflict thesis" which claims a methodological, factual, and political conflict between science and religion [75]. Although this thesis has been refuted by many scholars [76,77], the general public might still carry the same conception about the conflict between science and religion. Rios et al. showed that Christians are stereotyped as being low in science competence [78].

With respect to the religious beliefs of the American public, 90\% expressed their belief in God or a universal spirit $[79,80]$ with majority identifying themselves as Christians (77\%-65\% from 2011 to 2018) [81,82]. In contrast to the general public, $72.2 \%$ of the members of the National Academy of Sciences expressed their disbelief in God, with the highest rate of disbelief among physical scientists [83]. Another study reported that $31.2 \%$ of natural and social scientists from 21 elite universities in the U.S. identified themselves as atheist and a further $31 \%$ as agnostic [84]. This skepticism is not confined to the belief in God but extends to views on religion. For example, about one-third agreed with the statement that "There is very little truth in any religion." Interestingly, physicists had the highest rates of skepticism compared to other disciplines [84]. These findings indicate that there is likely a negative bias towards religion in general within the physics community. As a general trend, there is a negative correlation between the ranking of the university and religiosity of faculty members, which means it is less likely to find a professor who is a believer in an elite university compared to other kinds of institutions [85].
Disproportionate representation of religious individuals in the sciences indicates that the sciences may be less attractive to people with strong religious backgrounds.

Several factors can contribute to this phenomenon. In addition to the tension that some religious groups may find between their faith and scientific theories, there is evidence of a more general negative bias towards religious people in science. For example, some literature even tries to connect religiosity to low intelligence [86]. In addition, when sociologists were surveyed about whether they would hire someone if they knew the candidate was an evangelical Christian, $39.1 \%$ said they would be less likely to hire that candidate-there were similar results with other religious groups, such as Mormons (LDS) or Muslims [87,88]. This is while religious individuals (especially Christians) are aware of the negative stereotypes and biases against them which affects their interest and performance in science [78].

In terms of the connection to femininity, women in the U.S. are more likely to consider religion as "very important" in their lives (60\% women compared to $47 \%$ men) [89]. Furthermore, American women are more likely to pray daily compared to men (64\% vs $47 \%$ ). On all the standard measures of religious commitment examined in PEW research center's report, Christian women were found to be more religious than men [90]. Considering the negative bias towards religious individuals, women will be affected more, possibly exacerbating reasons that lead to the lower representation of women in science, technology, engineering, and mathematics (STEM) in general, and physics in particular.

\section{Physics and outward expression of femininity}

How people dress is an especially privileged symbol that is key to understanding the way they see themselves and represent themselves to others, both as individuals and as members of a group, such as women [91]. Thus, being "feminine," including how one dresses, is something that an individual acts out in order to be recognized as a certain type of person, in this case, being a woman [92]. The culture of what constitutes feminine expression permeates the fashion industry and serves to reinforce and reproduce these expressions, as well as change them [93]. These images of what constitutes being feminine also permeate society through popular media culture, which is particularly influential for adolescent girls [94]. Some aspects of feminine expression include having longer and/or styled hair, wearing makeup or jewelry, wearing particular types of clothing such as dresses, skirts, or heels, and even dressing in nice clothes in general $[95,96]$.

Furthermore, studies have found that exhibiting feminine expressions can signal to others that an individual is not suited for science $[5,95,96]$ and female students themselves have been found to opt out of such expressions when they 
choose a physics pathway $[42,97,98]$. This is a consequence of the fact that such feminine expressions are not representative of physical expressions that signal that a person is a member of the physics community. For example, Gonsalves described how feminine dress (such as wearing dresses and high heels) would look out of place in the physics community. She concluded that makeup, dresses, and heels tend to demonstrate a focus on one's self, and in physics it is expected that attention must be paid more to one's research. This incongruence between outward expressions of femininity and being a physicist has been found to lead to disruptions in identity for young women in physics [42].

\section{Physics, communal goals, and femininity}

Communal goals refer to individual aspirations which focus on others such as working with others and benefiting society [99]. Agentic goals focus more on individual agency, i.e., the self. While individuals can have both communal and agentic goals, in the West, women report a greater valuing for communal goals as compared to men [99] and girls have been found to be more cooperative and person oriented [100]. On the other hand, traditional gender roles emphasize agency for men [101], and boys have been found to be more dominant, independent, and competitive, which are traits associated with an agentic orientation [100]. These genderbased goal attributions have sometimes been generalized to the extent that some authors have gone so far as to consider "communal" and "agentic" as characterizing "feminine" and "masculine," respectively [27].

STEM broadly, and physics or physical science specifically, are seen as fields that fulfill communal goals less than other fields [101-103]. Students who have higher endorsement of communal goals are significantly less likely to be interested in STEM fields [101] and less likely to develop physics identities [102,104]. Furthermore, when interventions focus on the communal characteristics of STEM fields, a significantly higher level of interest is observed amongst women [101]. This indicates that messaging related to fields of study, which transmit underlying cultural norms and values, has an effect on individuals' interests and the unconscious or conscious choices they make regarding who they are and who they want to be. Unlike communal goals, agentic or intrinsic goals have been found to be positively related to the development of physics identities $[102,104]$. While agentic goals are more associated with masculine stereotypes [101], research has found no significant difference between female and male students or physical scientists in terms of agentic goal preference $[102,105]$. This supports the likelihood that the incongruence between a feminine identity and STEM or physics identity is due to perceptions related to communal goals rather than agentic goals [101].

\section{E. Physics, peer influence, and femininity}

Gender socialization starts from early childhood and parents play a primary role in communicating gender roles [106-108]. Early adolescence is considered a critical point in shaping male and female self-conceptions and attitudes. At the same time, as children grow older, the role of peers increases in their social lives [109] and the need for peer acceptance becomes a central concern for adolescents [5]. However, popularity among peers, especially at early adolescence, is not determined by academic achievement of students [110] and in some contexts, academic achievement has a negative effect on the popularity of students [110-112].

As adolescents mature, peers also play a very significant role in shaping gender identities [113]. Peer influence can manifest through pressure to conform to stereotypical gender norms and lack of conformity can be punished through sanctioning, teasing, or bullying by peers $[114,115]$. In contrast adolescents who describe themselves as gender typical tend to be more popular among their peers [114,116]. These norms, in line with the previous discussion, are often focused on how a person looks [72] in order to impress the opposite gender [62] rather than academic achievement. Interestingly, liking or disliking of certain school subjects can also be used to express certain kinds of gender identities. Thus, sex typing of school subjects serves as a guide for personal interest and choice [5]. For example, Hannover and Kessels showed that $46 \%$ of German students labelled physical science as a "boy" subject [49]. In a similar study, Kessels [5] showed that both boys and girls dislike girls who excel in physics. The prior research makes it clear that peers likely play a significant role in the process of shaping gender identity and driving young women away from pursuing physics.

\section{RESEARCH QUESTIONS}

In this paper, we examine the cultural experiences that are formative for attracting women to physics in Muslim majority countries and compare our findings to what has been found in the literature for several Western countries, including the United States. Since several MM countries (with available data) have a higher representation of female students in physics programs than typical for Western countries [15,16], it is important to understand how and why women who opted into physics in these MM countries were influenced by their cultures. Examining the influence of culture will help to frame a systematic understanding of the mechanisms by which certain students might opt in or out of a career in physics. Furthermore, this understanding will help to create programs and initiatives to shift cultural narratives that artificially impede the participation of any group. As such, our guiding research questions were

1. What are the lived cultural experiences (i.e., with family, peers, physics community, and broader 
society) of women physicists from MM countries with respect to their gender and physics identity?

a. What are the cultural factors shaping gender identity and what is understood as feminine in MM countries? What are the similarities or differences of gender identity (femininity) in MM countries and the U.S. (Western context)?

b. What is the relationship between femininity and physics identity in MM countries? How does this compare to the U.S. (Western context)?

\section{METHODS}

This study takes a phenomenological approach to examine the lived cultural experiences of women physicists trained in MM countries, especially with respect to the relationship between their gender identity and physics identity. The study consisted of seven interviews with female physics faculty members at U.S. universities who have a background in MM countries.

\section{PARTICIPANTS}

To identify potential participants, the websites of universities with medium to large physics programs were examined to identify potential participants. Female faculty members with a background education from MM countries were identified based on their CVs or other information provided on their academic institution's website. In addition, snowball sampling was used where interviewees identified other prospective participants. Thirty faculty members were contacted via email and seven agreed to participate. Table I depicts the participants (using pseudonyms), the MM country in which they were trained prior to coming to the U.S. (for these participants, also their national origin), and their age group. Five of seven participants have the physics background. Two of them have a background in EE, one in experimental physics and the rest are theoretical physicists. While each of the participants are at research active institutions, we cannot provide further institutional information to protect the anonymity of our participants. The interview was arranged based on the availability of the faculty member.

TABLE I. Participants, MM country in which they were trained, and their age group.

\begin{tabular}{llc}
\hline \hline Pseudonym & MM country & Age group \\
\hline Shams & Bangladesh & $50-60$ \\
Sarah & Iran & $30-40$ \\
Fatima & Jordan & $30-40$ \\
Alya & Lebanon & $30-40$ \\
Farah & Pakistan & $50-60$ \\
Wajiha & Saudi Arabia & $30-40$ \\
Nadia & Turkey & $30-40$ \\
\hline \hline
\end{tabular}

\section{INTERVIEWS}

Interviews were conducted over Zoom software with one exception which was over the phone. Interviews were conducted by the first author and included 30 questions with the possibility of follow up questions. Each interview took about 1 to $1.5 \mathrm{~h}$. Interviews were recorded and transcribed in order to conduct a thematic analysis. The interview protocol followed a chronological order with questions from childhood to adulthood of the participants. The questions were designed to capture cultural experiences which led participants to pursue and succeed in physics. In addition, the interview contained questions regarding participants' reflections on the experiences with and expectations of their family, friends, physics community, and broader society.

\section{ANALYSIS}

We took a phenomenological approach to find the common themes emerging from our interviews. The process included coding for segments in the interviews that addressed participants' experiences with their gender identity and engagement with physics. Furthermore, subcodes were used for the types of people or contexts (e.g., family, school, society) that participants were interacting with in forming their identities. These codes were compared across cases and five different themes emerged regarding the congruity or incongruity between gender and physics identities. It should be mentioned that not all of these themes were present in all the interviews. However, each theme emerged in several interviews, which led us to build five different hypotheses regarding the cultural factors leading women from MM countries to pursue physics. We present these themes in the next section.

\section{RESULTS AND DISCUSSION}

Given the complexity of the themes that emerged, we combine the presentation of the results and discussion. Thus, for each theme, the results are presented followed by a discussion that ties back to the literature.

\section{A. Social interaction, single-sex education, and femininity in MM countries}

Our interviews revealed that in MM countries less interaction was encouraged with people of the opposite gender. Fatima explained this practice while talking about the educational difference between Jordan and the U.S.:

Let me tell you, for example [in Jordan] it's not really common that the girls become friends with boys from the religious and culture side. (Fatima)

Further limiting interactions between female and male students, especially in the developmental and schooling years, our interviewees from Jordan, Bangladesh, Pakistan, 
and Saudi Arabia studied in single-sex schools before entering college.

Furthermore, despite being in coeducation environments in college, several of our participants minimized interactions with men and kept these interactions formal and to the point regarding the purpose of the interaction. For example, Farah described her own negotiating process of when to talk in physics classes with mostly men in this way:

I'm relatively social person. I like people. But I would prefer to not to talk because of obvious reasons. So, I will talk to class, but in a very limited way. (Farah)

Interestingly, after coming to the U.S., she observed the same tendency among the students she taught who are from MM countries:

I had two [female] students from Saudi Arabia, and different countries...Iranian students I had. They are much more comfortable with us [women faculty], and they treat more like friendly with us. On the other hand, with male colleagues, they don't do that. On the other hand, when it comes to male Americans, they are more friendly with my male [Muslim] colleagues because I have some [religious] limitations. (Farah)

Not only did participants moderate their own social interactions carefully, the requirements or expectations related to social interaction and other appropriate gender behaviors also shaped their career decisions. Farah, who was initially interested in going to medical school or doing her degree in chemistry, decided to continue in theoretical physics.

Oh, I wanted to go to chemistry, but I was not able to go to chemistry because the chemistry labs were usually scheduled in the evening. So I did theoretical physics and I think that worked out very well in the sense that I totally have to stay in the evening at home. (Farah)

It is interesting that Farah ended up pursuing an area of physics, in which women in Western contexts are highly underrepresented, for reasons related to gender expectations. Note that lab chemistry, which she opted out of, tends to be more interactive than theoretical physics. Pursuing theoretical physics allowed her to work from home, which was appropriate based on gender expectations in her context. This type of decision making to accommodate gendered expectations has also been observed in Western contexts, albeit in different ways. For example, women in medical fields have been found to opt into areas such as general practice instead of surgery specializations in order to accommodate children and family life $[117,118]$. Given the fact that interaction between opposite genders was limited for most of our participants (through single-sex schooling, minimizing interactions in mixed environments, or opting into less interactive fields), it is likely that the women in our sample were less exposed to subtle and overt comparisons with their male peers or colleagues. As such, unlike Western contexts, they were less likely to see their participation in physics as exceptional or out of the norm $[42,97,98]$. For example, Nadia explained that gender issues were not very salient for her before coming to the U.S.:

Of course I'm a woman, I know I'm a woman, I identify as a woman as well. I always identified as a woman. But I only started thinking about that identification and what it means, only in the last five years or so [after coming to the U.S.] basically. (Nadia)

Other participants also expressed similar sentiments in terms of feeling a lack of stereotypes about physics as a masculine major. Wajiha, when asked about whether certain fields were more or less appropriate for women in her culture, commented:

Culturally speaking, physics is not something that is a question mark...Everyone is fine with it. (Wajiha)

For Fatima, studying electrical engineering was something very normal and she was surprised, after coming to the U.S., that others found her participation in electrical engineering surprising:

Whenever [in the U.S.] I'm telling them that I am in electrical engineering, they get shocked. "Wow, electrical engineering. How could you do that?" I was not really feeling that it's something hard to do. I was shocked because they are shocked. (Fatima)

Collectively, this evidence suggests that due to the limited nature of certain types of social interactions experienced by the women in our study, especially with respect to men in physics contexts, they may have been less exposed to strongly gendered views of physics that affect persistence. More specifically, these experiences include single-sex physics education prior to college, limiting interactions with male peers and colleagues to essential work-related needs, and opting into fields that meet gender behavior expectations (e.g., being able to work in less interactive environments at home).

As reviewed earlier, prior research has found significant gains for girls in single-sex classes in some contexts [5966] but not others [67-70]. Although several of the participants mentioned experiencing single-sex education, they did not consciously perceive an effect of this education other than feeling that their experience in the U.S. was qualitatively different (e.g., "I was shocked, because they are shocked" referring to how she felt individuals in the U.S. reacted to her gender in a physics-related field). In the 
West, "single-sex schools have been prestigious and private and with selective admission policies" that admit students with stronger academic and socioeconomic background [119]. In contrast, single-sex education in many MM countries is common in public schools; coeducation is more typical of private schools [120]. This is while singlesex education has been found to have the largest positive effects for less advantaged students [121] like those from working class families. Supporting this supposition, four out of the seven participants in our study come from working class families.

Another consideration when comparing the previously cited literature from Western contexts and our data from MM contexts are the stereotypes with regards to being social. Several studies have found that women are more likely to be socially connected $[42,43]$ and yet perceptions of scientists/physicists are the opposite [48-50]. The social reserve expressed by several participants in our study, as well as the limited interactions with male peers/colleagues, may make the presumption of a scientist or physicist being less socially interactive a seamless boundary for women in our study. In other words, their culturally formed gender identity may be more congruent with having a physics identity, particularly in coeducational settings where they are more socially reserved. Furthermore, studies focused on the nature of gendering in STEM find that gendered stereotypes may be less salient in MM contexts $[122,123]$. For example, Sharepoure et al. reported that for Iranian girls, engineering was their favorite subject [123]. This is in contrast with studies that find young girls in the U.S. become disinterested in engineering at early ages [124]. Similarly, Murphy et al., in a comparative study on 9-12 year-old children's attitudes to school science in Oman and Ireland, found that the gendering of interest in science topics is much less in Oman compared to Ireland [122].

\section{B. Religion, science, and femininity in MM countries}

Contrary to the perception of tension between science and religion in Western contexts, many of our interviewees expressed religion as a motivation for pursuing physics. In her interview, Shams described an experience she had prior to college:

I went to a library that I think it was an American library [in my country]. There I found a book about astronomy. Then when I read that book, I found something beyond this Earth, comets, stars, galaxies and I was also very religious. So, I said wow, the creation of Allah is going very beyond us and it fascinated me. (Shams)

She felt no contradiction between her interest in science and her religious beliefs. In fact, her religious conviction mobilized her interest for what she called "the creation of Allah" that is "beyond us." For Shams, it was not just that science and religion were in neutral harmony with each other; she saw religion as the strongest guide and motivations in her career choice.

I used to read Quran, the translation, and I found that Allah is asking us to learn about the mystery of His creation. I said that I should do that so He [God] would be pleased. (Shams)

Similarly, Wajiha generally expressed religious motivations for pursuing science saying:

There is a lot of motivation [from my religion] to go and explore and work hard, and look at the skies. (Wajiha)

Unlike Shams whose religious motivation was more intrinsic, Wajiha also expressed practical religious motivations such as working hard. Similarly, Farah and Fatima also considered their practical work ethic in physics (education and teaching) as part of their religious practice.

I know Islam is very much into education, and for me, actually I go with that teaching that ... education is a kind of ibadat [worship]. (Farah)

The religion, maybe this is the way I'm thinking, makes you always try to do all of the things good. I mean add some as much as possible, so you want to be a good person, you want to do a good job in your work, because you want to get closer to your God. (Fatima)

Similar to Shams whose driving motivation was her relationship to God ("...I should do that so He would be pleased"), Fatimah linked her thoughts and actions (doing "a good job in your work") to her relationship to God ("because you want to get closer to your God"). For Fatima, it was a two-way relationship where she was pleasing God but God was also source of assistance for her in the endeavors leading to her academic success:

So that's why, for example, when I entered into the university, I wanted to get the scholarship just to help my father, because I saw he passed through many things in his life, bad things, so I wanted to be next to him. I'm sure God would reward me for that. I always used to pray that I get a good score in the high school and in the university so that I can go and continue my study. God is always next to me. (Fatima)

For these participants, religion did not avert them from pursuing physics, but helped them in choosing physics and pursuing it.

Our findings are consistent with the Pew global attitude report [125], which asked participants from 17 countries about the importance of religion in their life. Among these countries, 12 nations reported that religion is very important for them with 8 nations having more than $90 \%$ of people considering religion as very important. Interestingly, 7 out of 
these 8 countries are MM countries. The importance of religion is projected in a quote by Nadia on the opinion of her mother about religion:

Their first and foremost priority has always been that I grow up as a good Muslim. And my mom would always say, always, always. "Nothing you do matters in school or academia or in life, if you are not a good Muslim." (Nadia)

Considering the intersection between religious identity and physics identity is likely important for understanding the differences in female participation in physics in Western versus MM contexts. In the West, prior research has found that women are more likely to identify themselves as religious and religious communities have been found to, at times, be at odds with scientific communities [90]. Unlike Western countries, in MM countries men and women have been found to have similar levels of religious commitment [90]. As a result, religiosity may not disadvantage women from pursuing physics in these contexts. Furthermore, there may be less tension and greater overlap between religious identity and physics identity in MM countries as described by our participants above.

\section{Outward expression of femininity in MM countries}

Our interviews revealed that physical expressions of femininity in MM countries, particularly in public or social settings outside the family environment, are considerably different than what has been reported for Western contexts. The highly valued outward expressions of femininity in public spaces, including educational environments, are all tied to expressions of modest clothing and adornment, e.g., less attractive, loose-fitting clothing, less makeup and jewelry, etc. Farah noted that this modest expression is directly linked to the religiousness of a person but not always expressed with a headscarf:

So I am very religious still I think. The difference is that I am religious even I don't wear scarf. But I'm pretty moderately dressed and everything. (Farah)

Similarly, Fatima explained that getting closer to God is her purpose of wearing a scarf and it became part of her identity.

Ifelt this is one of the things that will bring me closer to Allah's path and I know that I am obliged as a Muslim woman to do that. It became part of me and my character, I cannot imagine myself without it and I am happy that I still keep it. (Fatima)

Nadia explained how she adjusted her outward expression of femininity in the West and her home country in order to fit into the norms of femininity in two different contexts:
You know, I try not to be too loud [in Turkey], especially if there are other people around. I also control how I dress, I don't dress too [Western style] feminine in Turkey when I go back, in my hometown, for cultural reasons. (Nadia)

For Nadia, the expression of femininity in the West is considered inappropriate in her home country and replaced with an expression of femininity that is more modest. Although Nadia expressed feeling that she fit into both contexts (felt like a "normal woman" in each), she did demonstrate instances of code-switching expressions of femininity. Farah described the cultural emphasis on modest expression by describing her father's point of view:

He [my father] never said that not to put makeup because it is bad. He would say, "People who put makeup, they just want to look attractive. But make your personality attractive, not the look. (Farah)

This resonated with Farah as implying that the function of modest expression was to divert the attention from physical characteristics to internal characteristics. This function for modest expression within Muslim communities has also been expressed in other work [126].

In Western literature, Muslim women are portrayed as oppressed, with physical clothing being an indicator of this oppression, in contrast with Western women who are more liberated and free [24,127]. However, participants in our study did not express the view that feminine physical expression through modest clothing was an oppressive state for them. For example, Fatima explained that:

Many people in Jordan wear Hijab, it is kind of part of culture and religion, since many people accept it, it did not affect negatively by any means my social interaction. (Fatima)

Furthermore, research focused on understanding the perspectives of Muslim communities has shown that modest dress can have an empowering effect for women in the community [126,128,129]. For example, Siraj reported that women in her study felt more confident expressing their character and their intentions in social settings [114]. They have also been found to cross gender boundaries while maintaining their feminine identity [128] and perceive that they are more than just their bodies and appearance [129].

As noted before, the outward expression of physical attractiveness is not valued in the physics community as an expression of membership [42,97,98]. However, it is valued as an expression of feminine identity in Western contexts $[95,96]$. Thus, young women in the West may experience an incongruence between their feminine and physics identities $[42,98]$. However, women from MM countries, whose femininity is not defined through their outward 
expression of physical attractiveness, may not perceive an incongruence in their gender identity and physics identity. Furthermore, if femininity through modest outward expression emphasizes intellectual aspects for these women from MM contexts, as the literature and our interviews propose, femininity may be perceived as more congruent with perceptions of being a physicist. Particularly since individuals who express physics identities often focus on intrinsic aspects [104] and are evaluated by others in the field based on perceptions of these aspects (e.g., innate ability) [4].

\section{Communal goals and femininity in MM countries}

Similar to the prior literature on women's goals in Western contexts, the importance of communal goals for women can also be inferred from our interviews.

However, several of our interviewees connected physics to their communal goals making it more congruent with their gender identities. In other words, physics was not seen as a subject that serves only agentic goals. Shams, who got interested in physics through astrophysics, was questioned by her parents about her choice of physics. To explain what physics is to her parents, she used communal goals to describe the importance of physics:

When I expressed my intention to my parents, they asked what is physics?! And I said that it was about the planets and outside the earth and how it could save humanity. (Shams)

Similarly, Farah also affirmed the communal goal of preserving human life as motivation for doing her research:

I wanted to save human life... and that's the part of the reason I started biophysics study. I work in microbiology part, but I'm studying bacteria, how the bacteria changes with the technological development. I wanted to contribute something in the survival of human life. (Farah)

Alya's path to physics indicated another type of communal motivation with respect to improving how physics is taught to students:

...part of the problem with students hating physics is that concepts sometimes are explained to them in a way that is more complicated than it really is. So I took that as kind of a challenge, that I wanted to major into physics so that I can teach physics in a better way than I had been taught. (Alya)

Another manifestation of communal goals appeared in Fatima's interview. She wanted to do good in her major to be able to get a scholarship. However, this was not because of her agentic goal for mastery in the field, but it was to help the financial situation of her family: ...when I entered into the university, I wanted to get the scholarship just to help my father, because I saw he passed through many things in his life, bad things, so I wanted to be next to him. (Fatima)

These statements indicate that these students viewed physics as affording communal goals, albeit in different ways. Drawing on the broader literature, it is possible that the general public in MM countries may consider physics (as a scientific field) to be somewhat more communal in terms of the field's ability to contribute to society than in Western contexts. Cross-cultural studies hint at such a trend. For example, Sjøberg and Schreiner reported that youth in Malaysia and Bangladesh, two MM countries, consider science more important for society than youth in England [130]. This gap gets even wider when asked about the benefit of science compared to its harms.

It is worth noting that the perception of being agentic as a masculine trait and communal as a feminine trait has been contested in the literature. Theories of social stratification [131] claim that the content of gender stereotypes varies based on cultural core values. For example, Cuddy et al. showed that Korean culture considers men to be more communal than women [132]. It has also been posited that men from MM countries might be more communal compared to Western contexts and specifically the U.S. [133]. For example, in an international study on IBM male employees which used Western notions of masculinity, the men in the sample from the United States were rated more masculine than feminine and Iranian men had an equal score in feminine and masculine traits [133]. This could explain why Alya was shocked to see a high level of individualism in the U.S. compared to Lebanon.

One of the things that were a bit shocking, and I think a little bit disappointing is the lack of social interactions and social support. There's a lot of individualism here [the U.S.], even among graduate students, and so that was kind of a very contrasting type of interactions that I wasn't used to (Alya).

Given the evidence, it may be the case that a greater emphasis on communal values in physics is an artifact of the generally greater value placed on communality, for both men and women, in MM cultural contexts. Thus, cultural context can have a meaningful impact on the practice of physics as well as the practitioners. In support, research has found that in communal cultures compared to individualist cultures, people define themselves and act in different ways [134]. More specifically, people from communal cultures have been found to define themselves more in terms of their group membership, prioritize group goals over individual goals, pay less attention to internal processes as determinants of social behavior, and tend to be more self-effacing amongst other factors [134]. Furthermore, religious cultures, in this case the Islamic culture, have been found to place more emphasis on communal values [135]. 


\section{E. The role of family in MM countries}

Our interviews revealed the strong role of parental influence on the career pathways of participants. In the conversation about their path to physics, several participants emphasized the role of family repeatedly. Note that there was not a single participant who brought up friends or peers during the conversation even though the influence of school and interactions at school were part of the interview. Sarah described that after arriving in the U.S., one of the first things her parents did was to register her at a local library. This helped instill and emphasize the value for learning and ultimately exposed her to the world of science:

I would always read actually at the library. I was a member of the library from the first day we came here.

That was where I learned most of my science. (Sarah)

Similar to Sarah, Farah expressed that valuing knowledge and prioritizing learning and education by family members was a reason for her continuing her education:

The reason why I started [higher education] was mainly because of my love for my parents, I don't know if I go back, I think that has played a role because my mom used to mention, "Oh, I saw a girl. She was educated." My mom was very much pro-education and she used to idealize the educated girl. (Farah)

Not only was education highly valued, but families also had high expectations from their daughters in terms of their achievements and pushed them in that direction. Sarah explained how her mom, believing in her abilities, convinced the school administration to put her in advanced level courses:

I think early on my mom did push to have me in the more advanced student courses. We had two tracks starting, I want to say sixth grade. I was in the advanced track. I had harder courses, and I had the higher level math. My mom did actually have to ask for that for me. (Sarah)

Similarly, Wajiha's father pushed her to come to the U.S. in order to actualize her talent and to have a more challenging and better quality education:

I think my father saw that I was very interested in science, and he saw I used to be ... In the summer, I used to work on math problems and physics problems, take his physics and math books and read through them and try to crack some of the problems. So he saw that I was sort of not only curious, but I was serious about it. So he was one of the people who pushed me into applying for a scholarship and going abroad (Wajiha).

This push for academic achievement and expectations that their daughters worked hard to reach their goals is part of the family values that Alya called "tough love."
While, in general, parental involvement has a positive role on students' academic achievement [136-138], family values and academic expectations are directly related to the degree of these achievements [139-141]. This valuing translates into family actions that support persistence (e.g., Sarah's mother advocating for her enrollment in higher level classes, Wajiha's father verbally encouraging her to pursue further opportunities), which were summarized by Sarah as

I think they were my biggest supporters all my life in terms of pushing my academic interests, giving me opportunities, making sacrifices so I can take those opportunities (Sarah).

In addition to the positive effect of family and parental involvement on the academic opportunities and achievement of our interviewees, family also played a role in career decision making for some of the interviewees like Fatima:

I was really free in my choices. They wanted me to try, do whatever you want, but at the end when I was kind of frustrated, then my father came and he started to convince me that this choice is better than this choice (Fatima).

Similarly, Sarah allowed her father to guide her career decision saying,

I think mostly because I felt like I want to do physics. My dad told me, "You will have more options in electrical engineering, and it's applied physics." Basically that's why. It wasn't a big analysis, because I trusted my dad... (Sarah).

For our participants, however, parental involvement in career decision making was not always in favor of choosing physics for a variety of reasons. Alya, who described her parents wanting her to be a doctor or engineer, saw a physics degree as limiting her to teaching as a profession in Lebanon:

...most common career option is to be a high school teacher, and that wasn't very...kind of, what my parents wanted me to do, in a sense (Alya).

For Shams, her parents' objection was because of her parents' lack of knowledge about physics and its benefit for the world:

They did not understand [physics] and asked what physics would do. I said to learn about the universe, meteor hitting the earth, etc. But they didn't see the benefit immediately (Shams).

This latter sentiment expressed by Shams about her parents' concerns is in agreement with our hypothesis 
about the importance of communal goals in MM countries. We see similarities and differences in the case of Wajiha. Wajiha, whose father was familiar with physics, and knew about the benefits of physics, encouraged her to pursue it. However when Wajiha decided to pursue theoretical physics, her father questioned her decision:

I guess at some point, my father questioned why I wanted to major in theoretical physics as opposed to something that has more applications in real life. That was the major thing that he disagreed with me about, I would say. He wanted me to specialize in something that had applications that benefit society... (Wajiha).

In the end, our interviewees were able to convince their parents about their career decision and in a case like Shams, they supported her even though they did not like her decision:

Though they were not very pleased (with my decision), but they supported me. (Shams)

It is important to note that our interviewees faced objections because of lack of career opportunities or perceptions about the limited applications of physics for benefiting others, but not because of stigmas related to gender appropriateness or the capability of these young women to do physics. Our findings about women's choice of physics is in stark contrast with those who propose that socioeconomic factors explain the higher participation of women in MM countries [142]. While this may be true for other fields (e.g., medicine, engineering), we found no evidence that this is the case for physics because it was not seen as a field that afforded job opportunities or a higher income. In general, for our interviewees, strong family support for education combined with beliefs about their daughters' capabilities (i.e., lack of stereotypes about physics as a masculine subject or being too difficult) helped facilitate their persistence in physics. In support, the AIP report from Iran on the status of women in physics, a country with a very high proportion of women amongst bachelor's degree recipients $(60 \%)$, attribute the high level of participation of women in physics to families investing in the education of girls among other factors [16].

\section{SUMMARY AND CONCLUSION}

In order to facilitate the participation of women in physics, this study explored the effect of culture on the congruence or incongruence between physics and feminine identities in MM countries as compared to the literature focused on Western contexts. Deviating from a gender orientalist approach, we focused on evidence drawn from the lived experiences of women physicists from MM contexts to better understand the ways in which feminine identities might intersect or conflict with constructing physics identities. This was juxtaposed with findings and prior research from Western contexts. Our results suggest that femininity and gender appropriate behaviors in MM countries may be shaped in ways that make them more congruent with demonstrating a physics identity compared to Western contexts. In particular, there were five emergent hypotheses or themes regarding the congruity or incongruity of gender or physics identities that we summarized in Table II.

The first theme relates to the nature of social interactions. Women in Western contexts are perceived as better in communication and being socially connected $[26,42,43]$. This is while physicists are stereotyped as individuals with poor social skills who work alone $[46,48]$. Hence, there is a likely incongruence between physics and femininity in broader perceptions. Yet within physics classes where active engagement is critical to learning, male students have been found to dominate teacher-student interactions [51,52] with female students more reticent to engage in ways that facilitate physics identity development [57]. In contrast, our data reveal that because of single-sex education and the limited nature of interactions between opposite genders in MM contexts, young women are not influenced by the presence of young men while forming their physics identity in school. In addition, the cultural emphasis on modesty as a feminine characteristic makes feminine identities in these contexts more congruent with the perception of physicists as discussed further below.

The second theme relates to the role of religion. While being religious is an attribute that is more strongly associated with women in the U.S., it is negatively associated with scientists, including physicists $[83-85,89,90,143]$. Hence, a subtle incongruence is prevalent between feminine and physics identities with respect to religiosity. In MM countries, religion, on average, plays a more important role in the personal and social life of individuals, for both men and women equally $[90,125]$. Our results reveal that religious motivations were important for many of our participants' choice to pursue science. As such, there may be a greater congruence between religion and science in MM contexts as well as less of a tie between religiosity and femininity to begin with, thus making any incongruence less gendered.

The third theme relates to physical expressions of femininity. In Western contexts, one of the expressions of femininity is through physical attractiveness [95,96,145, 146], while in MM countries the more valued outward expressions of femininity in public spaces, are tied to expressions of modest clothing and less adornment $[126,128,129]$. Our data support this finding for several of the female physicists in our sample. Since attractiveness is not an attribute of being a physics person from the standpoint of the physics community $[5,42,97,98,144]$, females from MM countries who express their femininity through modest clothing may not feel as much incongruity between their gender identity and their physics identity as compared to women in Western contexts. 
TABLE II. Hypotheses emerging from the interviews.

\begin{tabular}{|c|c|c|}
\hline Gendered experience & Physics identity & Hypotheses \\
\hline $\begin{array}{l}\text { MM data: Single sex K-12 schools } \\
\text { are very common in MM countries. } \\
\text { Less interaction is encouraged } \\
\text { between opposite genders. }\end{array}$ & $\begin{array}{l}\text { MM data: Girls shape their physics } \\
\text { identity without being overshadowed by } \\
\text { boys' presence in our data. Physics is } \\
\text { considered a major that requires less } \\
\text { interaction. }\end{array}$ & $\begin{array}{l}\text { a. Greater support for physics identity } \\
\text { development for women in MM } \\
\text { countries as they form it in single } \\
\text { sex settings. }\end{array}$ \\
\hline $\begin{array}{l}\text { Western data: Students primarily } \\
\text { experience co-education throughout } \\
\text { schooling. Women are seen as } \\
\text { better in communication } \\
\text { and being social }[26,42,43] \text {. }\end{array}$ & $\begin{array}{l}\text { Western data: Many girls are marginalized } \\
\text { and treated as less competent in physics } \\
\text { in the presence of boys. Physicists are } \\
\text { perceived as individuals with poor } \\
\text { social skills, working alone } \\
\text { in their labs or their offices } \\
{[46,48,51-54]}\end{array}$ & $\begin{array}{l}\text { b. Greater congruence between } \\
\text { gender and physics identity } \\
\text { for MMC women with regards } \\
\text { to social roles of being } \\
\text { less interactive. }\end{array}$ \\
\hline $\begin{array}{l}\text { MM data: Religion has been found } \\
\text { to be equally important to women } \\
\text { and men [90]. } \\
\text { Western data: Women are more } \\
\text { likely to report being religious [90]. }\end{array}$ & $\begin{array}{l}\text { MM data: Many of our interviewees } \\
\text { expressed religious motivations } \\
\text { for pursuing physics. } \\
\text { Western data: Scientists are } \\
\text { seen as areligious }[83,84,143] .\end{array}$ & $\begin{array}{l}\text { In MM countries, religiosity does not } \\
\text { disadvantage women in physics } \\
\text { over men. }\end{array}$ \\
\hline $\begin{array}{l}\text { MM data: Public expressions of } \\
\text { femininity emphasize modesty } \\
\text { rather than physical attractiveness. } \\
\text { Western data: One of the expressions } \\
\text { of femininity is through physical } \\
\text { attractiveness }[145,146] \text {. }\end{array}$ & $\begin{array}{l}\text { Western data: Physical attractiveness } \\
\text { is not valued or recognized } \\
\text { in the physics community } \\
{[42,144] .}\end{array}$ & $\begin{array}{l}\text { In MM countries, women's expressions of } \\
\text { modesty match values of the physics } \\
\text { community about not caring about } \\
\text { physical appearance more than Western } \\
\text { expressions of femininity through } \\
\text { physical attractiveness. }\end{array}$ \\
\hline $\begin{array}{l}\text { MM data: Being communal } \\
\text { is perceived as both masculine } \\
\text { and feminine [133]. }\end{array}$ & $\begin{array}{l}\text { MM data: Our interviewees found } \\
\text { ways of fulfilling their communal } \\
\text { goals through physics. } \\
\text { Physics can be } \\
\text { considered communal. }\end{array}$ & $\begin{array}{l}\text { In MM countries, since communal } \\
\text { aspects are valued by both women } \\
\text { and men, being communal may not } \\
\text { disadvantage women in physics } \\
\text { over men. }\end{array}$ \\
\hline $\begin{array}{l}\text { Western data: Being communal } \\
\text { is considered more of a feminine } \\
\text { characteristic }[99-101,147,148] \text {. }\end{array}$ & $\begin{array}{l}\text { Western data: Physicists are } \\
\text { perceived } \\
\text { as not being communal } \\
{[96-98,148,149] .}\end{array}$ & \\
\hline $\begin{array}{l}M M C \text { data: Family plays a major } \\
\text { role in the career paths of women. }\end{array}$ & $\begin{array}{l}\text { MMC data: Physics is not perceived as } \\
\text { masculine by family members. }\end{array}$ & $\begin{array}{l}\text { In MM countries, women are not } \\
\text { considered less competent in } \\
\text { physics by their family members. }\end{array}$ \\
\hline $\begin{array}{l}\text { Western Context: Family's influence } \\
\text { decreases in adolescence with an } \\
\text { increasing role of peers }[5,109,150] \text {. }\end{array}$ & $\begin{array}{l}\text { Western Context: Physics is } \\
\text { considered a masculine } \\
\text { subject by peers }[5,49] \text {. }\end{array}$ & \\
\hline
\end{tabular}

The fourth theme relates to the perception of being communal as a more feminine characteristic [27,99$101,147,148]$, while physics is considered as not serving communal goals [96-98,148,149]. As a result, female students may again feel incongruence between their gender identity and physics. In our data, the women physicists had communal goals and values similar to those found for women in Western contexts. However, they found ways of reconciling the goals of physics with their communal motivations. It may be the case that women physicists who grow up in Western cultural contexts also negotiate communal goals in similar ways; future research should focus on studying this. It could also be the case that women are not singled out from men for their communal goals in MM countries compared to the West, since men in other cultures have been found to be more communal $[122,123]$.

Thus, the women in our study may not have felt relatively higher levels of incongruence between their physics identities and communal values when compared to their male physics colleagues. This is another direction for future research.

Finally, the fifth theme is related to the role of family and peers on gender identity and the educational achievement of female students. Families play a significant role in shaping the gender identity and educational motivation of preteens [106-108]. However, in Western contexts, 
family influence can be superseded in later adolescence by peers as the role of peers increasingly shapes their identities $[5,109,150]$. This likely results in the enforcement of more stereotypical gender identities, at least with respect to physics. However, in our data, families played a very strong role throughout the education path of women physicists with little to no influence of peers mentioned. Family support, which includes high expectations and the belief of parents in their daughters' capabilities in the physical sciences facilitated their persistence in physics. However, families also raised concerns about the value of physics careers, concerns that have also been raised by parents in Western contexts with regards to advanced coursework such as physics [151].

\section{IMPLICATIONS, LIMITATIONS, AND RECOMMENDATIONS}

There are some practical implications for our work. First, it may be important to explicitly deconstruct unconscious stereotypic notions about the incongruence of physics and femininity. Prior research has found that explicit discussions about these issues can be beneficial [70,104,152154]. Second, as a community, we need to begin to recognize expressions of femininity as congruent with physics, rather than incongruent, by becoming more conscious and reflective about how we judge the competence of individuals who express feminine characteristics $[42,97]$. This active reflection may help to mitigate actions that convey a view of femininities as deficits to physics mindedness, particularly in Western contexts [42].

There are several limitations of this work. First, we did not have a comparison group of female physicists trained in Western contexts but rather based our comparison by drawing on the extant literature. Thus, to gain a better understanding, future work will include interviews from Western contexts. Another limitation is that our interviewees are female physicists who all persisted in their path and secured faculty positions. As such, their experience might be different from the average female student in physics. To understand the experiences of female physics students, the authors plan to extend the study to undergraduate physics students from select MM countries. In addition, our interviewees are individuals who decided to come to the U.S. for their graduate studies. Their experience is likely different from female physicists who remained in MM countries, especially in terms of experiencing glass ceilings in progressing to higher ranks [155]. We have to mention that MM countries are different in their language, traditions, and cultural experiences. In this paper, we focused on similarities and general themes that were common among our participants (from different MM countries) with regards to femininity and physics identities. However, understanding the differences in cultural experiences across MM countries is also important and a direction for future case studies focused on specific countries. Finally, given the different rates of participation in physics for women at the undergraduate level between several MM countries and Western countries, we focused on examining several possible differences between these contexts. However, it is important to note this does not rule out many possible similarities (e.g., communal goals) and cross-cultural studies should focus on these aspects also.

\section{ACKNOWLEDGMENTS}

The authors would like to thank Mohsin \& Fauzia Jaffer Center for Muslim World Studies at Florida International University as well as distinguished postdoctoral program at College of Arts, Sciences, and Education (CASE) at Florida International University for supporting this project.

\section{APPENDIX: INTERVIEW PROTOCOL}

Interview protocol is composed of 30 questions and designed to capture cultural experiences of participants regarding their family, friends, physics community, and broader society.

1. Can you please introduce yourself and tell me a little about yourself, your current position, where you got your degrees and what they were in.

2. What was the occupation and education level of your parents?

3. How many siblings do you have? What is their level of education? Their career?

4. What type of family did you have and what type of person they wanted you to be? What was their expectation from you as a daughter?

5. What was your personality as a child? Do you have any science related memory from your childhood?

6. How much important was your education for your parents? What was the lowest degree and the number of schooling years they expected from you?

7. Can you describe your high school? What type of friends did you have?

8. What was the kind of activities you used to do at school? Do you remember how much time did you spend on doing your home works/school works? What was your hobbies and what kind of activities you used to do out of school?

9. How much time you used to spend on watching TV? What type of programs were your favorite?

10. What type of students where considered popular? Did you have lots of friends at high school and what are the impacts of friends in your life?

11. What are things that inspired you as a teenager? What were your dreams as a teenager?

12. What was your favorite course in high school? Why was it your favorite?

13. Did you have any teacher or family member affecting your career choice? What was special about them? 
14. Why did you decide to go into physics? What is special about physics? What are your goals from doing physics?

15. Talk a little bit about the reaction of your parents and friends about your choice. Is there any major that you would have liked to pursue but there was not enough cultural support for it? What was the support or discouragement towards pursuing physics if any?

16. Did you have in mind to get your $\mathrm{PhD}$ at the time you entered university?

17. Do you need special talent to do good in physics? What are the requirements of being good in physics?

18. As a student, did you have enough time to spend on the other aspects of life? What are the other aspects of life that are important for you?

19. Who is a good role model for women in your opinion? What makes her someone to be followed?

20. What are the characters of a good woman? What are the characters of a good human being?

21. Do you think that physicists are single minded? Do you think that physicists do not have good social skills? Why?
22. Do you think that physics is an important for the society? Are the physicists important for the society? What are the changes that women physicists can make in the society? Please explain.

23. Do you encourage your children to pursue physics? Why?

24. Do you feel you have work/life balance? How do you manage to balance family life and your profession?

25. Do you think that there is a contradiction between spirituality and academic work?

26. Do you think that a physics make you a better person? In what way?

27. As a woman, do you think that your experience was somehow different from the male students?

28. How much do you think that you belong to the physics community?

29. Who is a role model physicist? What makes him/her as someone to be followed?

30. How does being a scientist affect your way of life? Do you think you would be a different person if you were not a physicist?
[1] R. Skibba, Women in physics, Nat. Rev. Phys. 1, 298 (2019).

[2] A. M. Porter and R. Ivie, Women in Physics and Astronomy, 2019 (AIP, New York, 2019), https://www .aip.org/statistics/reports/women-physics-and-astronomy2019.

[3] J. Blue, A. L. Traxler, and X.C. Cid, Gender matters, Phys. Today 71, No. 3, 40 (2018).

[4] S. J. Leslie, A. Cimpian, M. Meyer, and E. Freeland, Expectations of brilliance underlie gender distributions across academic disciplines, Science 347, 262 (2015).

[5] U. Kessels, Fitting into the stereotype: How genderstereotyped perceptions of prototypic peers relate to liking for school subjects, Eur. J. Psychol. Educ. 20, 309 (2005).

[6] U. Kessels, M. Rau, and B. Hannover, What goes well with physics? Measuring and altering the image of science, Br. J. Educ. Psychol. 76, 761 (2006).

[7] A. Zohar and B. Bronshtein, Physics teachers' knowledge and beliefs regarding girls' low participation rates in advanced physics classes, Int. J. Sci. Math. Educ. 27, 61 (2005).

[8] P. Whiteley, The gender balance of physics textbooks: Caribbean and British books, 1985-1991, Phys. Educ. 31, 169 (1996).

[9] M. Lorenzo, C. H. Crouch, and E. Mazur, Reducing the gender gap in physics e ducation, Am. J. Phys. 74, 118 (2006).

[10] S. J. Pollock, N. D. Finkelstein, and L. E. Kost, Reducing the gender gap in the physics classroom: How sufficient is interactive engagement?, Phys. Rev. ST Phys. Educ. Res. 3, 010107 (2007).

[11] J. Lave and E. Wenger, Situated Learning: Legitimate Peripheral Participation (Cambridge University Press, Cambridge, England, 1991).

[12] S. Traweek, Beamtimes and Lifetimes. The World of High Energy Physicists (Harvard University Press, Cambridge, MA, 1988).

[13] R. K. Unger, Toward a redefinition of sex and gender, Am. Psychol. 34, 1085 (1979).

[14] J. Marecek, M. Crawford, and D. Popp, On the construction of gender, sex, and sexualities, in The Psychology of Gender, 2nd ed., edited by A. H. Eagly, A. E. Beall, and R. J. Sternberg (Guilford, New York, 2004), pp. 192-216.

[15] M. Mohsen, H. Hosni, H. Mohamed, A. Gadalla, H. Kahil, and H. Hashem, Egyptian women in physics: Progress and challenges, AIP Conf. Proc. 1697, 060015 (2015).

[16] A. Irajizad, F. Roshani, and A. Izadi, Improving the status of Iranian women in physics, AIP Conf. Proc. 1697, 060024 (2015).

[17] A. S. Nurullah, Globalization as a challenge to Islamic cultural identity, Int. J. Interdiscip. Soc. Sci. 2, 45 (2008).

[18] A. Palmer and A. Gallab, Islam and Western culture: Navigating terra incognita, in Religion and Popular Culture: Studies on the Interaction of Worldviews, edited by D. A. Stout and J. Buddenbaum (University of Iowa Press, Ames, 2001), pp. 109-124.

[19] S. H. Nasr, The Heart of Islam: Enduring Values for Humanity (Harper Collins, San Francisco, 2002). 
[20] S. H. Nasr, Science and Civilization in Islam (Harvard University Press, Cambridge, MA, 1968).

[21] J. M. Halstead, An Islamic concept of education, Comp. Educ. Rev. 40, 517 (2004).

[22] A. W. Boulanouar, The notion of modesty in Muslim women's clothing: An Islamic point of view, N.Z.J. Asian. Stud. 8, 134 (2006).

[23] E. W. Said, Orientalism (Penguin, London, 1978).

[24] R. Terman, Islamophobia and media portrayals of muslim women: A computational text analysis of U.S. news coverage, Int. Stud. Q. 61, 489 (2017).

[25] S. Hamid, Between orientalism and postmodernism: The changing nature of Western feminist thought towards the Middle East, Hawwa 4, 76 (2006).

[26] S. T. Fiske, A. J. Cuddy, and P. Glick, Universal dimensions of social cognition: Warmth and competence. Trends Cognit. Sci. 11, 77 (2007).

[27] W. Wood and A. H. Eagly, Two traditions of research on gender identity, Sex Roles 73, 461 (2015).

[28] S. L. Bem, The measurement of psychological androgyny, J. Consult. Clin. Psychol. 42, 155 (1974).

[29] J. T. Spence and R. L. Helmreich, Masculinity \& Femininity: Their Psychological Dimensions, Correlates, and Antecedents (University of Texas Press, Austin 1978).

[30] S. Sinclair, C. D. Hardin, and B. S. Lowery, Self-stereotyping in the context of multiple social identities, J. Pers. Soc. Psychol. 90, 529 (2006).

[31] E. W. Close, J. Conn, and H. G. Close, Becoming physics people: Development of integrated physics identity through the Learning Assistant experience, Phys. Rev. Phys. Educ. Res. 12, 010109 (2016).

[32] P. W. Irving and E. C. Sayre, Conditions for building a community of practice in an advanced physics laboratory, Phys. Rev. Phys. Educ. Res. 10, 010109 (2014).

[33] C. Fracchiolla, B. Prefontaine, and K. Hingo, Community of practice approach for understanding identity development within informal physics programs, Phys. Rev. Phys. Educ. Res. 16, 020115 (2020).

[34] N.W. Brickhouse, Embodying science: A feminist perspective on learning, J. Res. Sci. Teach. 38, 282 (2001).

[35] A. Sfard, On two metaphors for learning and the danger of choosing just one, Educ. Res. 27, 4 (1998).

[36] G. S. Aikenhead, Science education: Border crossing into the subculture of science, Stud. Sci. Educ. 27, 1 (1996).

[37] M. N. Maddock, Science education: An anthropological viewpoint, Stud. Sci. Educ. 8, 1 (1981).

[38] P. Phelan, A. Davidson, and H. Cao, Students' multiple worlds: Negotiating the boundaries of family, peer, and school cultures, Anthrop. Educ. Q. 22, 224 (1991).

[39] V. B. Costa, When science is "another world": Relationships between worlds of family, friends, school, and science, Sci. Educ. 79, 313 (1995).

[40] L. B. Krogh and L. B. Thomsen, Studying students' attitudes towards science from a cultural perspective but with a quantitative methodology: border crossing into the physics classroom, Int. J. Sci. Educ. 27, 281 (2005).

[41] K. Ethier and K. Deaux, Hispanics in ivy: Assessing identity and perceived threat, Sex Roles 22, 427 (1990).

[42] A. Gonsalves, Physics and the girly girl-there is a contradiction somewhere: Doctoral students' positioning around discourses of gender and competence in physics, Cult. Stud. Sci. Educ. 9, 503 (2014).

[43] Y. J. Weisberg, C. G. Deyoung, and J. B. Hirsh, Gender differences in personality across the ten aspects of the big five, Front. Psychol. 2, 178 (2011).

[44] D. Knox, K. Vail-Smith, and M. Zusman, The lonely college male, Int. J. Men's Health. 6, 273 (2007).

[45] E. Lang-Takac and Z. Osterweil, Separateness and connectedness: Differences between genders, Sex Roles 27, 277 (1992).

[46] S. M. Clancy and S. J. Dollinger, Photographic depictions of the self: Gender and age differences in social connectedness, Sex Roles 29, 477 (1993).

[47] S. E. Cross and L. Madson, Models of the self: Selfconstruals and gender, Psychol. Bull. 122, 5 (1997).

[48] S. Cheryan, V. C. Plaut, C. Handron, and L. Hudson, The stereotypical computer scientist: Gendered media representations as a barrier to inclusion for women, Sex Roles 69, 58 (2013).

[49] B. Hannover and U. Kessels, Self-to prototype matching as a strategy for making academic choices. Why high school students do not like math and science. Learn Instr. 14, 51 (2004).

[50] M. Bruun, S. Willoughby, and J. L. Smith, Identifying the stereotypical who, what, and why of physics and biology, Phys. Rev. Phys. Educ. Res. 14, 020125 (2018).

[51] E. Gillibrand, P. Robinson, R. Brawn, and A. Osborn, Girls' participation in physics in single sex classes in mixed schools in relation to confidence and achievement, Int. J. Sci. Educ. 21, 349 (1999).

[52] J. Streitmatter, Single-sex classes: Female physics students state their case, School Sci. Math. 98, 369 (1998).

[53] T. A. Hughes, The advantages of single-sex education, Natl. Forum Educ. Admin. Supervision J. 23, 5 (2006).

[54] J. Wieselmann, E. Dare, E. Ring-Whalen, and G. Roehrig, "I just do what the boys tell me": Exploring small group student interactions in an integrated STEM unit, J. Res. Sci. Teach. 57, 112 (2020).

[55] U. Gneezy, M. Niederle, and A. Rustichini, Performance in competitive environments: Gender differences, Q. J. Econ. 118, 1049 (2003).

[56] M. Niederle and L. Vesterlund, Do women shy away from competition? Do men compete too much?, Q. J. Econ. 122, 1067 (2007).

[57] H. B. Carlone, The cultural production of science in reform-based physics: girls' access, participation, and resistance, J. Res. Sci. Teach. 41, 392 (2004).

[58] E. E. Maccoby, The Two Sexes: Growing Up Apart, Coming Together (Belknap Press, Cambridge, MA, 1998).

[59] U. Kessels and B. Hannover, When being a girl matters less: Accessibility of gender-related self-knowledge in single-sex and coeducational classes and its impact on students' physics-related self-concept of ability, Br. J. Educ. Psychol. 78, 273 (2008).

[60] A. L. Booth and P. J. Nolan, Choosing to compete: How different are girls and boys?, J. Econ. Behav. Organ. 81, 542 (2012).

[61] P. Murphy and E. Whitelegg, Girls in the Physics Classroom: A Review of the Research on the Participation of Girls in Physics (Institute of Physics, London, 2006). 
[62] P. Haussler and L. Hoffmann, An intervention study to enhance girls' interest, self-concept, and achievement in physics classes, J. Res. Sci. Teach. 39, 870 (2002).

[63] AAUW, Separated by Sex: a Critical Look at Single-Sex Education for Girls (American Association of University Women Educational Foundation, Washington, D.C., 1998).

[64] H. Brutsaert and M. Van Houtte, Girls' and boys' sense of belonging in single-sex versus co-educational schools, Res. Educ. 68, 48 (2002).

[65] A. Stables, Differences between pupils from mixed and single-sex schools in their enjoyment of school subjects and in their attitudes to science and to school, Educ. Rev. 42, 221 (1990).

[66] P. Murphy and E. Whitelegg, Girls and physics: Continuing barriers to 'belonging', Curric. J. 17, 281 (2006).

[67] C. Sharp, D. Hutchison, C. Davis, and W. Keys, The takeup of advanced mathematics and science coursessummary report, National Foundation for Educational Research Report, 19 (School Curriculum and Assessment Authority, London, 1996).

[68] P. C. LePore and J. R. Warren, A comparison of single-sex and coeducational catholic secondary schooling: Evidence from the National Educational Longitudinal Study of 1988, Am. Educ. Res. J. 34, 485 (1997).

[69] R. Harker, Achievement, gender and the single-sex/coed debate, Br. J. Sociol. Educ. 21, 203 (2000).

[70] Z. Hazari, G. Potvin, R. M. Lock, F. Lung, G. Sonnert, and P. M. Sadler, Factors that affect the physical science career interest of female students: Testing five common hypotheses, Phys. Rev. ST Phys. Educ. Res. 9, 020115 (2013).

[71] J. Hattie, Classroom composition and peer effects. Int. J. Educ. Res. 37, 449 (2002).

[72] F. A. Mael, A. D. Alonso, K. Rogers, and M. Smith, Single-Sex Versus Coeducational Schooling: A Systematic Review (U.S. Department of Education, Washington, DC, 2005).

[73] L. H. Parker and L. J. Rennie, Teachers' implementation of gender-inclusive instructional strategies in single-sex and mixed-sex science classrooms, Int. J. Sci. Educ. 24, 881 (2002).

[74] L. Bian, S. J. Leslie, and A. Cimpian, Gender stereotypes about intellectual ability emerge early and influence children's interests, Science 355, 389 (2017).

[75] J. Draper, History of the Conflict between Religion and Science (Appleton, New York, 1874).

[76] P. Harrison, That religion has typically impeded the progress of science, in Newton's Apple and Other Myths about Science, edited by R. L. Numbers and K. Kampourakis (Harvard University Press, 2015).

[77] Science \& Religion: A Historical Introduction, edited by C. A. Russel and G. B. Ferngren (Johns Hopkins University Press, Baltimore, MD, 2002).

[78] K. Rios, Z. H. Cheng, R. R. Totton, and A. F. Shariff, Negative stereotypes cause Christians to underperform in and disidentify with science, Soc. Psychol. Pers. Sci. 6, 959 (2015).

[79] Gallup, More than 9 in 10 Americans continue to believe in God (Gallup Poll, Washington, DC, 2011). Retrieved from http://www.gallup.com/poll/147887/americanscontinuebelieve-god.aspx.

[80] Pew Research Center, When Americans Say They Believe in God, What Do They Mean? (Pew Research Center, Washington, DC, 2018).

[81] Gallup, In U.S., 77\% identify as Christian (Gallup Poll, Washington, DC, 2012). Retrieved from http://www .gallup.com/poll/159548/identify-christian.aspx.

[82] Pew Research Center, In U.S., Decline of Christianity Continues at Rapid Pace (Pew Research Center, Washington, DC, 2019).

[83] E. J. Larson and L. Witham, Leading scientists still reject God, Nature (London) 394, 313 (1998).

[84] E. Ecklund and C. Scheitle, Religion among academic scientists: Distinctions, disciplines, and demographics, Social Probl. 54, 289 (2007).

[85] N. Gross and S. Simmons, The religiosity of American College and university professors, Sociol. Religion 70, 101 (2009).

[86] M. Zuckerman, J. Silberman, and J. A. Hall, The relation between intelligence and religiosity: A meta-analysis and some proposed explanations, Pers. Soc. Psychol. Rev. 17, 325 (2013).

[87] G. Yancey, Compromising Scholarship: Religious and Political Bias in American Higher Education (Baylor University Press, Waco, TX, 2011).

[88] G. Yancey, Recalibrating academic bias, Acad. Quest. 25, 267 (2012).

[89] Pew Research Center, America's Changing Religious Landscape (Pew Research Center, Washington, DC, 2015).

[90] Pew Research Center, The Gender Gap in Religion Around the World (Pew Research Center, Washington, DC, 2016).

[91] A. Rafaeli and M. G. Pratt, Tailored meanings: On the meaning and impact of organizational dress, Acad. Manag. Rev. 18, 32 (1993).

[92] J. Butler, Undoing Gender (Routledge, New York, 2004).

[93] C. Evans and M. Thornton, Fashion, representation, femininity, FEMS Microbiol. Rev. 38, 48 (1991).

[94] A. L. Press, 'Feminism? That's so seventies': Girls and young women discuss femininity and feminism in America's Next Top Model, in New Femininities (Palgrave Macmillan, London, 2011), pp. 117-133.

[95] S. Banchefsky, J. Westfall, B. Park, and C. M. Judd, But you don't look like a scientist !: Women scientists with feminine appearance are deemed less likely to be scientists, Sex Roles 75, 95 (2016).

[96] B. Francis, L. Archer, J. Moote, J. DeWitt, E. MacLeod, and L. Yeomans, The construction of physics as a quintessentially masculine subject: Young people's perceptions of gender issues in access to physics, Sex Roles 76, 156 (2017).

[97] M. Ong, Body projects of young women of color in physics: Intersections of gender, race, and science, Social Probl. 52, 593 (2005).

[98] L. Archer, J. Moote, B. Francis, J. DeWitt, and L. Yeomans, The "exceptional" physics girl: A sociological analysis of multimethod data from young women aged 
10-16 to explore gendered patterns of post-16 participation, Am. Educ. Res. J. 54, 88 (2017).

[99] A. B. Diekman, E. R. Brown, A. M. Johnston, and E. K. Clark, Seeking congruity between goals and roles: A new look at why women opt out of science, technology, engineering, and mathematics careers, Psychol. Sci. 21, 1051 (2010).

[100] T. Mujtaba and M. J. Reiss, What sort of girl wants to study physics after the age of 16 ? Findings from a largescale UK survey, Int. J. Sci. Educ. 35, 2979 (2013).

[101] A. B. Diekman, E. K. Clark, A. M. Johnston, E. R. Brown, and M. Steinberg, Malleability in communal goals and beliefs influences attraction to stem careers: Evidence for a goal congruity perspective, J. Pers. Soc. Psychol. 101, 902 (2011).

[102] C. Monsalve, Z. Hazari, D. McPadden, G. Sonnert, and P. M. Sadler, Examining the relationship between career outcome expectations and physics identity, in Proceedings of the 2016 Physics Education Research Conference, Sacramento, CA (AIP, New York, 2016), pp. 228-231.

[103] C. Morgan, J. D. Isaac, and C. Sansone, The role of interest in understanding the career choices of female and male college students, Sex Roles 44, 295 (2001).

[104] Z. Hazari, G. Sonnert, P. Sadler, and M. C. Shanahan, Connecting high school physics experiences, outcome expectations, physics identity, and physics career choice: A gender study, J. Res. Sci. Teach. 47, 978 (2010).

[105] P. M. Sadler, G. Sonnert, Z. Hazari, and R. Tai, Stability and volatility of STEM career interest in high school: A gender study, Sci. Educ. 96, 411 (2012).

[106] "UNICEF-Early Childhood-Early Gender Socialization". Unicef.org (UNICEF, New York, 2018).

[107] S. D. Witt, Parental influences on children's socialization to gender roles, Adoesc. 32, 253 (1997).

[108] H. P. Halpern and M. Perry-Jenkins, Parents' gender ideology and gendered behavior as predictors of children's gender-role attitudes: A longitudinal exploration, Sex Roles 74, 527 (2016).

[109] J. R. Harris, Where is the children's environment? A group socialization theory of development, Psychol. Rev. 102, 458 (1995).

[110] N. Meijs, A. H. N. Cillessen, R. H. J. Scholte, E. Segers, and R. Spijkerman, Social intelligence and academic achievement as predictors of adolescent popularity, J. Youth Adolesc. 39, 62 (2010).

[111] P. A. Adler and P. Adler, Peer Power: Preadolescent Culture and Identity (Rutgers University Press, New Brunswick, 1998).

[112] P. A. Adler, S. J. Kless, and P. Adler, Socialization to gender roles: Popularity among elementary school boys and girls, Sociol. Educ. 65, 169 (1992).

[113] C. J. Boyatzis, P. Baloff, and C. Durieux, Effects of perceived attractiveness and academic success on early adolescent peer popularity, J. Genet. Psychol. 159, 337 (1998).

[114] J. A. Jewell and C. S. Brown, Relations among gender typicality, peer relations, and mental health during early adolescence, Soc. Dev. 23, 137 (2014).

[115] K. Drury, W. M. Bukowski, A. M. Velásquez, and L. Stella-Lopez, Victimization and gender identity in single- and mixed-sex schools: Examining variations in pressure to conform to gender norms, Sex Roles 69, 442 (2013).

[116] S. K. Egan and D. G. Perry, Gender identity: A multidimensional analysis with implications for psychosocial adjustment, Dev. Psychol. 37, 451 (2001).

[117] E. L. Rangel, H. Lyu, A. H. Haider, M. Castillo-Angeles, G. M. Doherty, and D. S. Smink, Factors Associated With Residency and Career Dissatisfaction in Childbearing Surgical Residents, JAMA Surg. 153, 1004 (2018).

[118] J. de Costa, J. Chen-Xu, Z. Bentounsi, and D. Vervoort, Women in surgery: Challenges and opportunities, Int. J. Surg. Glob. Heal. 1, e02 (2018).

[119] S. Shah and C. Conchar, Why single-sex schools? Discourses of culture/faith and achievement, Cambridge J. Educ. 39, 191 (2009).

[120] E. M. King and M. A. Hill, Women's Education in Developing Countries: Barriers, Benefits, and Policies, A World Bank Book (The Johns Hopkins University Press, Baltimore, 1993).

[121] R. Salomone, Single-sex schooling: Law, policy, and research, in Brookings Papers on Education Policy, edited by D. Ravitch (Brookings Institution, Washington, DC, 1999), pp. 231-279.

[122] C. Murphy, A. Ambusaidi, and J. Beggs, Middle East meets West: Comparing children's attitudes to school science, Int. J. Sci. Educ. 28, 405 (2006).

[123] M. Sharepour, Gender role stereotypes among Iranian adolescents, J. Soc. Psychol. 145, 491 (2005).

[124] E. A. Dare and G. H. Roehrig, "If I had to do it, then I would": Understanding early middle school students' perceptions of physics and physics-related careers by gender, Phys. Rev. Phys. Educ. Res. 12, 020117 (2016).

[125] Pew Research Center, A Changing World: Global Views on Diversity, Gender Equality, Family Life and the Importance of Religion (Pew Research Center, Washington, DC, 2019).

[126] A. Siraj, Meanings of modesty and the hijab amongst Muslim women in Glasgow, Scotland, Gend. Place Cult. 18, 716 (2011).

[127] J. Minces, The House of Obedience: Women in Arab Society, translated by M. Pallis (Zed Press, London, 1980).

[128] F. El Guindi, Veil: Modesty, Privacy and Resistance (Berg. Fremson, Ruth, Oxford, 1999).

[129] D. Winchester, Embodying the faith: Religious practice and the making of a Muslim moral habitus, Social Forces 86, 1753 (2008)

[130] S. Sjøberg and C. Schreiner, How do learners in different cultures relate to science and technology? Results and perspectives from the project ROSE (the Relevance of Science Education), APFSLT 6, 1 (2005).

[131] C. L. Ridgeway, E. H. Boyle, K. J. Kuipers, and D. T. Robinson, How do status beliefs develop? The role of resources and interactional experience, Am. Sociol. Rev. 63, 331 (1998).

[132] A. J. Cuddy, E. B. Wolf, P. Glick, S. Crotty, J. Chong, and M. I. Norton, Men as cultural ideals: Cultural values moderate gender stereotype content, J. Pers. Soc. Psychol. 109, 622 (2015). 
[133] G. H. Hofstede, Culture's Consequences, International Differences in Work-Related Values (Sage Publications, Newbury Park, CA, 1984).

[134] H. C. Triandis, Individualism-collectivism and personality, J. Pers. 69, 907 (2001).

[135] N.S. Aziz and A.S. Ismail, The role of traditional Madrasa design in transforming Islamic education towards the development of societal communal values. Adv. Sci. Lett. 24, 4528 (2018).

[136] T. Ross, The differential effects of parental involvement on high school completion and postsecondary attendance, Educ. Policy Anal. Arch. 24, 1 (2016).

[137] S. A. Garbacz, K. C. Herman, A. M. Thompson, and W. M. Reinke, Family engagement in education and intervention: implementation and evaluation to maximize family, school, and student outcomes, Journal of school psychology 62, 1 (2017).

[138] V. Tárraga, B. García, and J. Reyes, Home-based family involvement and academic achievement: a case study in primary education, Educ. Stud. Math. 44, 361 (2017).

[139] S.S. Peng and D. Wright, Explanation of academic achievement of Asian American students, J. Ed. Res. 87, 346 (1994).

[140] P. D. Davis-Kean, The influence of parent education and family income on child achievement: The indirect role of parental expectations and the home environment, J. Fam. Psychol. 19, 294 (2005).

[141] R. R. Pearce, Effects of cultural and social structural factors on the achievement of white and Chinese American students at school transition points. Am. Educ. Res. J. 43, 75 (2006).

[142] G. Stoet and D. C. Geary, The gender-equality paradox in science, technology, engineering, and mathematics education, Psychol. Sci. 29, 581 (2018).

[143] Pew Research Center, Religion and Science in the United States (Pew Research Center, Washington, DC, 2009).

[144] H. B. Carlone, A. Johnson, and C. M. Scott, Agency amidst formidable structures: How girls perform gender in science class, J. Res. Sci. Teach. 52, 474 (2015).
[145] C. Skelton, B. Francis, and B. Read, Brains before 'beauty'? High achieving girls, school and gender identities, Educ. Stud. Math. 36, 185 (2010).

[146] V. S. Helgeson, Prototypes and dimensions of masculinity and femininity, Sex Roles 31, 653 (1994).

[147] J. S. Eccles and M. T. Wang, What motivates females and males to pursue careers in mathematics and science?, Int. J. Behav. Dev. 40, 100 (2016).

[148] R. M. Simon, A. Wagner, and B. Killion, Gender and choosing a STEM major in college: Femininity, masculinity, chilly climate, and occupational values, J. Res. Sci. Teach. 54, 299 (2017).

[149] L. L. Carli, L. Alawa, Y. Lee, B. Zhao, and E. Kim, Stereotypes about gender and science women $\neq$ scientist, Psychol. Women Q. 40, 244 (2016).

[150] S. Hashmi, Adolescence: An age of storm and stress, RAH 2, 19 (2013).

[151] J. M. Harackiewicz, C. S. Rozek, and C. S. Hulleman, and J.S. Hyde, Helping parents to motivate adolescents in mathematics and science: An experimental test of a utility-value intervention, Psychol. Sci. 23, 899 (2012).

[152] H. Cheng, G. Potvin, R. Khatri, R. Lock, L. Kramer, and Z. Hazari, The structure of student physics identity development through two high school interventions, in Proceedings of the 2018 Physics Education Research Conference, Washington, DC (AIP, New York, 2018).

[153] R. Lock and Z. Hazari, Discussing underrepresentation as a means to facilitating female students' physics identity development, Phys. Rev. Phys. Educ. Res. 12, 020101 (2016).

[154] E. S. Weisgram and R. S. Bigler, Effects of learning about gender discrimination on adolescent girls' attitudes toward and interest in science, Psychol. Women Q. 31, 262 (2007).

[155] C. Bagley, M. Abubaker, and A. Shahnaz, Woman and management: a conceptual review, with a focus on Muslim Women in management roles in Western and in Muslim-Majority countries, Open J. Business Manage. 6, 498 (2018). 